\title{
Diverse and Active Roles for Adipocytes During Mammary Gland Growth and Function
}

\author{
Russell C. Hovey • Lucila Aimo
}

Received: 26 July 2010 / Accepted: 6 August 2010 / Published online: 19 August 2010

(C) The Author(s) 2010. This article is published with open access at Springerlink.com

\begin{abstract}
The mammary gland is unique in its requirement to develop in close association with a depot of adipose tissue that is commonly referred to as the mammary fat pad. As discussed throughout this issue, the mammary fat pad represents a complex stromal microenvironment that includes a variety of cell types. In this article we focus on adipocytes as local regulators of epithelial cell growth and their function during lactation. Several important considerations arise from such a discussion. There is a clear and close interrelationship between different stromal tissue types within the mammary fat pad and its adipocytes. Furthermore, these relationships are both stage- and species-dependent, although many questions remain unanswered regarding their roles in these different states. Several lines of evidence also suggest that adipocytes within the mammary fat pad may function differently from those in other fat depots. Finally, past and future technologies present a variety of opportunities to model these complexities in order to more precisely delineate the many potential functions of adipocytes within the mammary glands. A thorough understanding of the role for this cell type in the mammary glands could present numerous opportunities to modify both breast cancer risk and lactation performance.
\end{abstract}

Keywords Mammary fat pad - Adipose .

Epithelial-stromal $\cdot$ Adipokine

R. C. Hovey $(\bowtie) \cdot$ L. Aimo

Department of Animal Science, University of California, Davis,

2145 Meyer Hall, One Shields Avenue,

Davis, CA 95616, USA

e-mail: rchovey@ucdavis.edu

\author{
Abbreviations \\ ER Estrogen receptor \\ IGF-I insulin-like growth factor-I \\ HGF hepatocyte growth factor \\ VEGF vascular endothelial growth factor
}

\section{Introduction}

Any discussion of processes involving mammary gland growth, differentiation, lactation or involution is generally centered about changes within the epithelial tissue [1-3]. However, a unique and fascinating aspect of mammary gland biology is the requirement for mammary epithelial cells to grow and function in a stromal environment referred to as the mammary fat pad [4]. Crucial to this environment are the resident adipocytes [5]. Whereas this depot of adipose tissue was once viewed as a relativelyinert matrix, it is now well-recognized that such a proposal is far from true [4]. Beyond the growth- and functionmodulating properties of the adipocytes, this environment ultimately dictates the extent to which the glandular epithelium of an individual can develop into a functional mammary gland [6], which may positively influence the amount of mammary gland growth and milk yield [7]. However, there are also notable variations within the mammary adipose tissue across species which can markedly impact states such as breast cancer that warrant recognition and discussion [5]. In this article we will review past and current evidence revealing how adipocytes, specifically within the mammary fat pad, can regulate epithelial growth and function, with a specific focus on the normal gland. We then summarize possible mechanisms by which adipocytes might exert their effects. Finally, we 
make brief mention of experimental approaches that have been used to dissect the roles of adipocytes in the mammary glands.

\section{Roles and Functions of Adipose Tissue}

Adipose tissue plays critical roles during homeostasis across all states in mammals, including during mammary gland growth and lactation. However, in considering a role for adipocytes in the mammary glands it is important to appreciate the unique and diverse properties of these fascinating cells. Several excellent articles provide an indepth review of this topic $[8,9]$. White adipose tissue is composed of adipocytes characterized as being unilocular, where the cytoplasm of each cell contains a single, large, cytoplasmic lipid droplet. By contrast, brown fat adipocytes are multilocular and thereby contain several lipid droplets with an interspersed cytoplasm. White adipose tissue is a principal site for lipid storage whereas brown adipose tissue serves a critical role during thermogenesis due to the expression of uncoupling protein-1 and its sympathetic innervation. These fat tissues also differ in their vascularization, which is much more pronounced in brown fat. While beyond the scope of this article, evidence also exists to suggest that white and brown adipose tissue can undergo transdifferentiation [10]. Along these lines, brown adipose tissue is often found in distinct depots but can also be interspersed among white adipose tissue [11].

\section{Adipose Tissue in the Mammary Glands During Development and Function}

\section{The Embryonic-neonatal Period}

The mammary fat pad undergoes significant changes during mammary gland growth and function. During embryogenesis the mammary anlage is intimately associated with a mesenchyme that serves critical roles during induction of the mammary epithelium [12]. At birth, the primitive epithelial structures lie juxtaposed to a depot of adipose tissue, although its presentation differs across species. In rodents, adipocytes of the mammary fat pad differentiate around days $16-17$ of fetal life [13], thereby enabling the ductal anlage to extend across its bounds and become positioned in a sizeable, well-developed fat pad by the time of birth [13]. In humans the ductal structures of neonates are often embedded within a connective tissue stroma [14, 15], but have also been found in close apposition with nearby islands of variably-sized vascularized, differentiated embryonic fat [14]. This embryonic fat tissue was characterized as having vascularized preadipocytes surrounded by collagen-IV, which is similar to that seen in the rodent mammary gland [15]. In the embryonic heifer the mamma- ry fat pad begins to develop around day 80 of a 9-month gestation [16] to become well-established by birth. At this stage there are notable connective tissue septa throughout its volume [5, 17]. A similar situation exists in neonatal ewe lambs $[18,19]$. In these species the epithelial elements are embedded within an intralobular stroma, separate from the adipose tissue. A micrograph depicting a rudimentary duct within the mammary gland of an immature postnatal Beagle bitch similarly reveals its position within a connective tissue stroma separate from adipocytes [20]. Likewise, our observations in pigs indicate that the epithelial ducts within the late-gestation fetus lie within a fibrous stroma at the edge of the clearly-demarcated embryonic fat pad (Madrak and Hovey, unpublished).

\section{Postnatal Development}

As discussed earlier within this issue [21], the mammary fat pad in the postnatal female is a collective term for the stromal environment into which the parenchyma develops. Many of its individual components are also discussed in detail elsewhere in this issue. However, brief mention will be made here about the relationship between these components and the mammary adipose tissue in which they develop and function. Bani-Sacchi and colleagues characterized the evolution of mammary adipose tissue of mice in detail, presenting the cytological progression of adipocytes and their evolution from perivascular mesenchymal cells [22]. This progression involved initial maturation of "pale" preadipocytes with well-developed organelles and few, small lipid droplets into "dark preadipocytes" that were undergoing active lipid accumulation. These preadipocytes then progressed to globular, multivacuolated adipocytes, and finally presented as mature, unilocular white adipocytes [22].

Matsumoto and colleagues described the nature of adipocytes and the vasculature in the inguinal mammary glands of ovariectomized, hormone-treated mice [23, 24]. In ovariectomized females, and in those treated with progesterone, they noted the presence of multilocular adipocytes specifically in the vicinity of the inguinal lymph node and the major blood vessels [23]. By contrast, estrogenized females had adipocytes that were predominantly unilocular, as was also observed in ovary-intact females [23]. Along these same lines, we have observed the increased mass of the mammary fat pads of estrogenized mice (unpublished observation). These data are consistent with the demonstration that estrogen induced hyperplasia of adipocytes within the mammary fat pad. This effect was amplified by relaxin, whereas relaxin alone induced adipocyte hypertrophy [22].

In order to study lactation-associated changes within the mammary fat pad during lactation, Matsumoto and 
colleagues starved mice and then examined adipocytes in the mammary glands in an attempt to mimic similar homeorrhetic changes during lactation [25]. These authors found that mammary adipocytes assumed a multilocular appearance during starvation, often as clusters of cells, resembling those present in the mammary glands during lactation. Interestingly, they also observed concurrent lipid droplet formation in the mammary epithelium, consistent with the results from recent studies that ablated mammary adipocytes [25].

Any discussion regarding the mammary adipose tissue microenvironment in mice should mention the fact that brown adipose tissue forms part of the thoracic mammary gland fat pad complex $[5,26]$. It is interesting that this microenvironment apparently supports normal development and function of the epithelium, consistent with the finding of Hoshino who achieved a high recovery rate for epithelium grafted to the interscapular depot of brown adipose tissue [5]. More recent evidence indicates that white and brown adipocytes may be able to transdifferentiate between the two cell types [27], raising the possibility that mammary epithelial cells (in mice at least) normally grow amongst both types of adipocytes (Fig. 1). Along these lines, a microarray approach identified a brown adipose-specific gene signature in the mammary glands of mice that was abundant in prepubertal females, and that was cold-inducible [28]. It is possible, however, that these findings reflect contamination of tissue samples by brown adipocytes from the thoracic mammary glands. Regardless, these combined data raise interesting questions about roles for white versus brown adipocytes in the mammary gland and their role(s) during growth and lactation.

The full process of vascular development within the mammary glands of mice is outlined in detail by others elsewhere in this issue [29]. Clearly, however, there is a crucial relationship between development of the mammary fat pad and the associated vasculature during postnatal development [23, 24, 30]. Master et al. identified that expression of several regulators of angiogenesis, including VEGF ligand and its receptors, were abundant in the mammary glands of mice at 2 weeks of age (which are primarily adipose tissue at this stage) during the same period that brown fat cell differentiation was being recorded [28]. Consistent with these data, we previously showed that adipocytes within the mammary fat pad developmentally express several VEGF isoforms, where the Flk-1 receptor was most abundant in the neonatal cleared fat pad [31]. Hence, it appears that early establishment of the vasculature throughout the mammary fat pad may depend on crosstalk with the adipocyte population and its development, consistent with findings for other adipose depots [31]. The coordinated, early development of the mammary adipose tissue and its associated vasculature [32] and the parallel expression of respective genetic markers during this window [28] coincides with recent evidence showing that adipocytes probably arise from a progenitor niche within the adipose vasculature [33]. Relative to the normal mammary gland, the surgically-cleared mammary fat pad maintains a normal vascular supply, although further angiogenesis and its hormonal induction required the presence of the interspersed mammary epithelium [30].

\section{The Pregnancy-Lactation-Involution Transitions}

The activity of mammary adipocytes is perhaps most obvious during the transitions from pregnancy to lactation, and into involution. Adipocytes within the mammary glands of rats increased their cross-sectional area by approximately $20 \%$ as they transitioned between the nonpregnant state and day 11 of gestation, and then maintained similar dimensions until day 20 of gestation [34]. These same observations were made by Elias et al. who emphasized that enlargement of the mammary glands during pregnancy is not accompanied by adipocyte depletion but rather parenchymal expansion [35]. Adipocytes within the mammary glands displayed an increased incidence of cell surface-associated vesicles during pregnancy that ultimately were most abundant during lactation [35].

Adipocyte function within the mammary fat pad during pregnancy is also both site-specific and epitheliumdependent. Whereas abdominal fat pads from mice had doubled their lipogenic rate (as measured by conversion of ${ }^{14} \mathrm{C}$-glucose to lipid) with the progression to pregnancy, lipogenesis within the cleared mammary fat pad remained static [36]. By contrast, adipocytes isolated from the intact mammary glands of pregnant females also doubled their lipogenic capacity compared to those in nulliparous females [36]. These data are consistent with those of Bandyopadhyay et al. [37] who found that the lipid content of cleared mammary fat pads remained constant during pregnancy, which was in marked contrast to the pronounced lipogenesis within abdominal fat.

While data is lacking for changes within the mammary adipose tissue in humans during pregnancy, there are notable differences between adipose tissue in the breast and other sites. Mammary adipocytes from postmenopausal women undergo less norepinephrine-stimulated lipolysis compared to those from premenopausal women, whereas femoral adipocytes maintained a constant response [38]. Furthermore, the relative proportion of fibroblasts to adipocytes in breast adipose tissue was similar to that for abdominal adipose tissue, where the incidence of both cell types was greater in breast adipose than in adipose from the hip [39]. Along these same lines, adipose tissue from the periphery of mammary glands in pregnant pigs was more metabolically active than peritoneal fat and displayed the 
greatest level of lipid mobilization between days 75 and 90 of gestation, coincident with rapid mammary growth [39].

Mammary adipose tissue undergoes significant changes during lactation that ultimately occur in support of milk production. Many of these findings related to the transition from pregnancy to lactation were made decades ago either through ultrastructural analysis [35] or via enzymatic assays $[40,41]$. Shortly after parturition adipocytes within the mammary glands of mice start to become depleted so that they present as variably-sized multilocular fat cells along with smaller unilocular adipocytes [35]. There are also striking site-specific differences in the metabolism of adipose tissues during lactation. Consistent with our own unpublished observations, the cleared mammary fat pad was consistently more resistant to lactation-induced lipolysis compared to adipose depots such as the parametrial fat pad $[35,36]$. This site-specificity is fascinating and raises questions as to whether white adipose tissue in the mammary gland is conditioned to be more responsive to local, epithelium-derived cues such as epithelium-secreted lipoprotein lipase. Indeed, adipocytes in close proximity to epithelial cells undergo more rapid depletion of their lipid stores than those in either the cleared fat pad or in distal areas of the fat pad separate from the mammary parenchyma [35, 42]. Hence, both local and systemic influences dictate lactation-induced lipolysis by mammary gland adipocytes during lactation.

Surprisingly, there is only a limited understanding and appreciation for the distribution and abundance of adipose tissue within the normal human breast [43] or its role and function during lactation [44]. Analysis of mastectomy specimens indicated that the fat volume within the breast among individuals ranged from 7 to $56 \%$ [45], while others provided a categorical classification that revealed similar variation [46]. By analyzing the lipid content of mammoplasty specimens, Lejour found that the fat content of breasts from individual women ranged from 2 to $78 \%$, with an average of $48 \%$ [43]. Hartmann and colleagues [44] employed ultrasound to characterize the incidence and distribution of adipose tissue within the breasts of lactating women. While adipose distribution within the left and right breasts was similar, there were pronounced differences between women regarding the abundance of adipose tissue in the breast, which ranged from $16-51 \%$. Subcutaneous, intraglandular and retromammary fat stores occupied, on average, approximately 24,7 and $7 \%$ of the lactating breast volume, respectively [44]. These simple descriptive studies not only emphasize how little is appreciated about the abundance of adipose tissue within the human breast at any stage, but also how inconsistent it is between individuals. Furthermore, whereas some studies found positive associations between breast fat content, age and obesity [43], others did not [45].
The mammary epithelium of rodents undergoes a wellcharacterized post-lactational regression during involution [2]. During this same period, adipocytes within the mammary glands replenish their lipid stores, first appearing as small unilocular cells approximately $48 \mathrm{~h}$ after weaning, then as fully-replenished unilocular adipocytes approximately 4 days later [35]. This replenishment of lipid in adipocytes within the involuting mammary glands appears to involve a crucial requirement for remodeling of the local extracellular matrix. When plasma kallikrein activity was blocked in involuting mice, thereby blocking plasminogen conversion to plasmin, adipocyte replenishment was also impaired [47]. When stromelysin or matrix metalloproteinase activity was blocked, mammary adipocytes were hypertrophic [48]. While the findings from these studies encapsulate multiple events, they certainly do highlight an important role for tissue remodeling during involutedinduced lipogenesis by mammary adipocytes.

There is a paucity of information regarding changes in the properties of mammary adipocytes in humans following lactation. However, in postmenopausal women the proportion of adipose tissue within the breast increases with age concomitant with a decrease in the parenchymal component [49].

In ruminants such as dairy cows the situation is different. The mammary epithelium occupies the former mammary fat pad during lactation, but then after involution (during the "dry" period) the epithelium only undergoes limited regression [50]. At this stage the associated stroma only consists of fibrous connective tissue [51]. While there are changes in the fibrous connective tissue during the dry period [52], any low incidence of adipose tissue in the udder of dry cows has not been quantified and likely does not change based on fat content of the udder [51]. From an observational standpoint it is worth noting that the udder of dry cows is sometimes anecdotally referred to as resembling a "wrung-out dishrag", reflecting a failure of the mammary gland to resume appreciable lipid deposition during this period.

\section{Mammary Adipose Tissue as a Source of Paracrine and Endocrine Molecules}

Depots of adipose tissue like the mammary fat pad have become recognized as a site for the synthesis of many diverse molecules (reviewed in [53]). The complex local environment of the mammary adipose tissue ultimately constitutes a reservoir of interstitial fluids that include both locally-secreted molecules and those assimilated from distal sites. Using a proteomics approach, Celis et al. identified over 350 proteins within mammary adipose tissue [54]. The provision of molecules in the local environment of the mammary adipose tissue also raises intriguing questions 
about how their presentation at the local level might be distinct from, or could modify, endocrine provision of some of these same factors. While a comprehensive review of adipose-derived molecules is beyond the scope of this review, several specific examples are worth mentioning given their potentially-important roles in the mammary gland.

For many years prolactin was considered to be exclusive to the anterior pituitary, then was subsequently found to be synthesized by cancerous breast epithelium [55]. Now it is clear that adipose tissue from various sites, including the mammary glands of rodents and humans, can synthesize prolactin $[56,57]$. What remains unclear is whether this locally-derived prolactin targets prolactin receptors on epithelial or, perhaps stromal, cells. Regarding this point, all prolactin receptor isoforms are expressed within the epithelium-free mammary fat pads of mice [58], and these undergo notable stage-specific changes in their expression. Specifically, the long form of the receptor maintains its expression in the mammary fat pad across all ages, whereas expression of the variant short forms declines at different rates during early life. Further potential for prolactin to impact adipocyte maturation specifically within the mammary gland is suggested by the fact that prolactin modifies the function of mammary stromal preadipocytes in vitro [59]. This finding is in keeping with the fact that preadipocytes from prolactin receptor knockout mice fail to differentiate in culture [60], where these same mice also have reduced adiposity in white fat depots [61]. Clearly, much remains to be established regarding any role for adipocyte-derived prolactin during prolactin-mediated growth and lactation. Separately, it is noteworthy that prolactin inhibits lipoprotein lipase activity in breast adipose tissue [62], which may have implications for the release of lipid from local adipose stores in the mammary glands either during neonatal development or lactation.

Considerable attention has been directed toward the ability of adipose tissue to synthesize estrogens through the expression of cytochrome aromatase $\mathrm{p} 450$. Support for the concept that adipose tissue is a site of estrogen biosynthesis has come from studies of the breast (reviewed in [63]). A recent, noteworthy analysis of transcription from the aromatase-encoding gene Cyp19A1 and its regulation in mice generated intriguing results [64]. Whereas appreciable aromatase expression was detected in gonadal and visceral fat depots, none was detected in the mammary glands of nulliparous 6 month-old female mice (that almost certainly contained both epithelial and stromal elements). Given the ability of epithelial cells to modulate stromal function, it is conceivable that the absence of Cyp19A1 expression in mammary adipocytes could be directed by the adjacent epithelium. Alternatively, as highlighted elsewhere in this review, the adipose environ- ment of the mammary fat pad may be distinct from other fat depots. Using cultured adipose tissue from cows, Feuerrman et al. identified that aromatase expression was prolactin-inducible, raising further possibilities for a local endocrine loop between local prolactin and estrogen biosynthesis [65]. Such a finding may be in keeping with the earlier demonstration that aromatase expression in the goat mammary gland was low, but increased during late gestation [66].

Adipocytes and the associated stromal cells within the mammary fat pad also represent a candidate target site for both endocrine-derived and local estrogens. Estrogen receptors (ER) have been detected in adipocytes and fibroblasts within the mammary fat pads of mice [67], heifers [68] and humans [69]. However, the precise roles for these receptors remain unclear, although studies using gene-ablated mice indicate an essential role for these stromal receptors during ductal growth in the mouse [70]. Further confusion regarding this matter arises when discussing the ER- $\alpha$ and $E R-\beta$ isoforms given that the predominant stromal isoform in mice appears to be ER- $\beta$ [71] whereas both isoforms have been localized to the stroma of the normal human breast [72]. Meanwhile, ER- $\beta$ was undetectable in the mammary gland stroma from heifers [73].

Stroma-derived insulin-like growth factor-I (IGF-I) has earned considerable attention as a potent paracrine effector of mammary gland growth. Several excellent reviews are available on this topic $[74,75]$. Kleinberg and colleagues have provided several lines of evidence demonstrating that the mammary fat pad provides essential, locallysynthesized IGF-I that promotes growth of the ductal epithelium. Furthermore, Richert and Wood localized IGFI mRNA expression within stromal tissue of the mammary fat pad, which clearly included adipocytes [76], consistent with the expression of IGF-I by subscapular adipose tissue in rats [77]. Along these lines, we established that IGF-I mRNA expression was increased in the proximity of the parenchymal tissue within the mammary glands of ewe lambs [78], whereas this was not the case in heifers [73]. This difference may reflect differences in the age or parenchymal composition of these species. One potentially-important finding regarding local IGF-I expression concerns its expression in the mammary fat pad compared to other adipose depots. Interestingly, in both rats [77] and heifers [73] there was the general finding that the inductive effects of estrogen on IGF-I expression occurred moreso in the mammary fat pad than in other adipose depots. These data further support the idea that adipocytes within the mammary glands may have unique properties compared to those at other sites.

Hepatocyte growth factor (HGF) was originally shown to be synthesized by mammary fibroblasts, but is also 
expressed by both adipocytes [79] and adipose-derived stem cells [80]. Mammary epithelial cells treated with HGF display a pronounced tubulogenic response in threedimensional culture, where HGF mediates effects of estrogen on the mammary stroma [81]. Transforming growth factor- $\beta$ similarly is expressed by components of the mammary fat pad [82] to potentially influence normal epithelial growth and morphogenesis [83].

There is now a widespread appreciation that adipose tissue within the body is an active endocrine organ that serves as the source for several metabolism-regulating hormones that have been coined "adipokines" [53]. While a full review of the functions and properties of all candidate adipokines is not possible here, it is appropriate to at least briefly mention observations related to the mammary fat pad. Significant interest is being directed toward the role for these various adipokines in the relationship between obesity and breast cancer risk [84].

Leptin is produced by adipocytes within the mammary gland [85], where its expression is increased by dietinduced obesity concomitant with reduced ductal development [86]. Likewise, a deficiency in leptin signaling has pronounced effects on the mammary fat pad and ductal development through unknown systemic mechanisms [87]. Interestingly, estrogen tended to increase leptin receptor expression in the mammary fat pad but not in other subcutaneous adipose tissue depots in heifers [88]. Another adipokine, adiponectin, is apparently indespensible for mammary gland growth in mice [89]. However, transgenic overexpression of adiponectin apparently suppresses ductal development [89], although the promoter used in these mice was not defined. Several other adipokines such as tumor necrosis factor- $\alpha$ and interleukins have also been implicated in the response of mammary adipocytes to obesity [90] or the growth-modulating effects of dietary conjugated linoleic acid [91].

Beyond this brief discussion of how certain adipokines affect the mammary epithelium, it is important to note that these same molecules have pronounced effects on other components within the mammary fat pad including the vasculature, the lymphatics, cells of the immune system, and the connective tissue. Such an example is vascular endothelial growth factor (VEGF) that is expressed by adipocytes within the mammary fat pad in an isoformspecific fashion during mammary development and lactation [31]. As a result, adipocytes within the mammary fat pad may regulate angiogenesis and, in turn, subsequent epithelial function during states such as lactation via their production of molecules such as VEGF [31] and HGF [92]. While a full discussion of this cell-cell interdependency within adipose tissue is not possible here, such a concept has been reviewed elsewhere [53]. Regardless, it has become clear, as raised elsewhere in this issue [21], that adipose tissue within the mammary fat pad not only affects the epithelium directly but also "cross-talks" with several other stromal compartments to modulate their important functions.

\section{Adipose Tissue as a Source of Lipids and Their Metabolites}

Adipocytes within the mammary glands are also highly responsive to a female's metabolic state. Of course, any metabolic changes are also manifest throughout the body, which hampers interpretations about specific roles for adipocytes within the mammary glands during these states. However, it is appropriate to at least briefly consider some of these data. For example, dietary energy intake, fat content and fat type have pronounced effects on mammary development in rodents. Specifically, a deficiency in dietary essential fatty acids impaired ductal and alveolar development $[93,94]$. Furthermore, increasing levels of dietary fat increases mammary growth [95] that is generally associated with adipocyte hypertrophy. Along these same lines a great deal of effort is currently being directed toward understanding the relationships between obesity and breast cancer risk in women that, at least in part, implicates roles for adipocytes in the mammary gland microenvironment. In a perhaps-similar situation, excess dietary energy intake was historically implicated in the suppression of mammary gland growth in heifers and lambs through increased accretion of lipid in the mammary fat pad and associated adipocyte hypetrophy [96]. However, this longstanding phenotype was recently attributed to rapid sexual maturation moreso than any direct effects of accelerated growth on the mammary epithelium [97].

Adipose tissue within the mammary glands also likely provides a local source of lipids and metabolites for the mammary epithelium. Epithelial cells within the mouse mammary gland are able to utilize fatty acids sequestered from adipocytes of the mammary fat pad [37], where the growth-promoting effect of medium conditioned by mammary adipocytes can be simulated by exogenous unsaturated fatty acids [98]. These fatty acids can then be metabolized to a variety of derivatives that have also been shown to have both positive and negative effects on epithelial cell growth and function [99]. In a recent study we also identified that aberrant expression of an n-3 desaturase in the mammary epithelial cells of nulliparous mice led to parallel, partial reproductive failure [100], further supporting the notion that the mammary glands may function as an endocrine organ [101].

Likewise, epithelial cells clearly induce lipolysis in adjacent mammary adipocytes during lactation [35, 102], presumably through the actions of epithelium-derived lipoprotein lipase [102]. In turn, these adipocyte-derived fatty acids can then be utilized for de novo fatty acid 
synthesis by lactating mammary epithelial cells. In addition, several groups have reported that exogenous unsaturated fatty acids might influence lactogenesis. Whereas Nandi and colleagues found that $\beta$-casein synthesis by primary mammary epithelial cells was increased by linoleic acid in culture [103], a recent report identified the opposite effect in that both oleic and linoleic acids promoted the degradation of hormone-induced $\beta$-casein [104]. This latter finding may be explained by time-dependent changes in the response of mammary epithelial cells to these fatty acids in culture [105]. Regardless, these data highlight the potential for local, adipocyte-derived fatty acids to modulate the differentiated function of mammary epithelial cells, in addition to their growth.

\section{In Vivo and In Vitro Models to Study Roles for Adipose Tissue in the Mammary Glands}

Any discussion regarding the role of the mammary stroma centers about elucidating the role for different cell populations, including adipocytes, during mammary gland growth and function. Of course this is not the simplest of issues. However, various models have been utilized that are worthy of discussion here, both for their utility and contributions.

Various in vitro methods have been developed and employed to assess the role for adipocytes in regulating the normal growth and function of mammary epithelial cells. Several groups have used approaches including enzyme-dissociated adipocytes, preadipocytes, or explants of mammary fat pad tissue $[98,106]$ to prepare conditioned medium for addition onto mammary epithelial cells. Separately, we have found utility in co-culturing mammary fat pad in a floating system [107], whereas others co-cast explants of mammary fat pad in collagen gels alongside epithelial organoids [108]. More recently, others have simulated both the physical (extracellular matrix) and cellular (preadipocytes) components of the mammary stromal environment using more elaborate culture models [109].

Early in vivo transplantation approaches provided some of the most convincing evidence that the mammary adipose environment is critical for mammary gland growth and development. Faulkin and DeOme's "cleared fat pad" surgical approach provided a model that has since become widely adopted wherein epithelial cells (with diverse backgrounds such as normal, precancerous, cancerous, xenografted and genetically-modified) can be transplanted into the adipose matrix of the mouse mammary fat pad [110]. We have applied this same cleared fat pad approach to other species including sheep [18] while others have done the same in heifers [111]. The importance of the adipose environment for the mouse mammary gland was subsequently clarified using this approach. For example, normal mouse mammary epithelial cells will develop upon transplantation to any adipose tissue depot [6] including brown adipose [112], although among the white adipose tissue depots the cleared mammary fat pad tended to support the most growth [6]. Likewise, transplantation of mammary grafts to subcutaneous sites failed to demonstrate any growth beyond the white adipose tissue [6, 113]. Further studies also raised the interesting question as to whether the mammary fat pad is immunologicallyprivileged compared to other adipose sites [113, 114], a proposal that was later called into question using immunogenic tumor cell lines [114]. However, this topic may warrant revisitation in light of the more-recent revelations regarding the role of the immune system in mammary gland growth. Interestingly, the location of the recipient fat pad can also dictate metastatic growth, where metastases from the mammary fat pad primarily arise in the lung whereas those transplanted into ovarian or mesenteric adipose tissues generally occur in the liver, spleen and diaphragm [115]. However, mammary epithelial cells from different species likely do not all have the same requirement for an adipose tissue environment that is found in the mouse. Similar to mouse mammary epithelial cells, normal epithelial cells from rats, but not tumor cells, also can fully repopulate the mammary fat pads of nude mice [116]. By contrast, mammary epithelial cells from both humans and cows fail to outgrow in this same adipose tissue environment, but instead form quiescent cysts [16]. As discussed by Sheffield, this outcome may well reflect the greater abundance of connective tissue stroma in these species [16]. That proposal has been validated through the recent establishment of the human-in-mouse model, wherein fibroblasts from human breast tissue facilitate the establishment and morphogenesis of human mammary epithelium [117]. Whether the same requirement for stromal supplementation holds true for epithelium derived from species including ruminants remains to be determined.

Genetically-manipulated animal models have also provided excellent opportunities to further probe specific roles for the adipose tissue environment within the mammary glands. One such approach was ablation of adipocytes by overexpression of the A-ZIP/F transcription factor under direction of the AP2 promoter [118]. From these mice it was proposed that ductal elongation, but not alveolar development and lactation, were adipocyte-dependent. However, additional negative metabolic outcomes in these mice potentially confound a full interpretation of their mammary phenotype. To address these issues, Scherer and colleagues recently generated FAT-ATTAC mice that allowed for stage-specific ablation of adipocytes using chemically-induced FKBP-caspase 8 dimerization [119]. It is noteworthy that while dimerization-induced apoptosis 
should occur in all adipose tissues of these females, the authors note that the mammary fat pad was more susceptible to these changes than other depots. Like the AP2-ZIP mice, these mice have a reduced incidence of terminal end buds (up to 4.4 fold) and impaired ductal elongation, although this difference ( $\sim 3 \mathrm{~mm}$ at $6 \mathrm{wk}$ of age) was not as pronounced as might be expected after the ablation of adipocytes. By contrast, adipocyte ablation in sexually-mature females promoted precocious alveologenesis, epithelial differentiation and secretion.

Recombination of genetically-modified epithelial and stromal tissues has also been a powerful tool for determining the function of the mammary fat pad and its components. While the list of such transplant recombinants has become extensive, it is worth noting that this approach has led to important findings regarding the role of hormone and growth factor receptors, extracellular matrix molecules, soluble factors and non-adipocyte components within the collective tissues of the mammary fat pad $[70,120]$. The ability of mammary epithelium to grow in adipose tissue has enabled these transplants to be performed either in the cleared mammary fat pad or as an epithelial-adipose recombinant under the kidney capsule [70].

These complex approaches obviously limit their use to study the role of the adipose microenvironment in humans. However, one approach worth mentioning in the context of adipose tissue function is breast fat grafting. This approach has gained recent widespread adoption for treating women in cases such as post-surgical disfigurement, genetic abnormalities or for breast augmentation [121]. Interestingly, grafted adipose tissue appears to be better-supported in the subcutaneous and interglandular sites relative to the retroperitoneal adipose depot $[121,122]$. While this method has attracted much discussion about its safety, it also has the potential to incorporate much of our current understanding about adipocyte stem cell function to breast biology [122]. Of course, the obvious major concern relates to whether any modification of the mammary adipose environment within the breast may influence a woman's breast cancer risk. Ultimately, such concerns will only be addressed by better-resolving the function of the mammary fat pad and its adipocytes in all species.

\section{Conclusions}

As outlined above, adipocytes within the mammary gland are clearly dynamic and crucial for the growth and function of the mammary epithelium. Yet, many questions remain unanswered. For example, it remains unclear whether adipocytes within the mammary glands are functionally distinct from those in other depots. Adipocytes in the mammary gland are also likely to modulate the function of other extra-epithelial cell types, such as those discussed in this issue. However, the full extent of these interrelationships is only beginning to surface. Likewise, mammary epithelial cells have an inherent requirement to reside among adipocytes in vivo, at least in mice. Why? Finally,
Fig. 1 Diverse relationships between adipose tissue and the mammary epithelium. $\mathbf{a}$ and $\mathbf{b}$ ) Photomicrographs of epithelial ducts within the \#3 thoracic mammary glands from the same pubescent female $\mathrm{Balb} / \mathrm{C}$ mouse at $55 \mathrm{~d}$ of age invested within a) unilocular, white adipose tissue and b) multilocular, brown adipose tissue. Both adipose tissue types are associated with the thoracic mammary glands in mice. Hematoxylin and eosin. c) Epithelial ducts growing within the mammary fat pad of a nulliparous female pig, invested within collagenous intralobular stroma beyond which lies unilocular white adipose tissue. d) Regressing alveoli within the mammary gland of a postlactational sow showing interspersed, lipid-filled adipocytes. Magnification is same for all panels, scale bar in panel $\mathrm{A}$ is $50 \mathrm{um}$
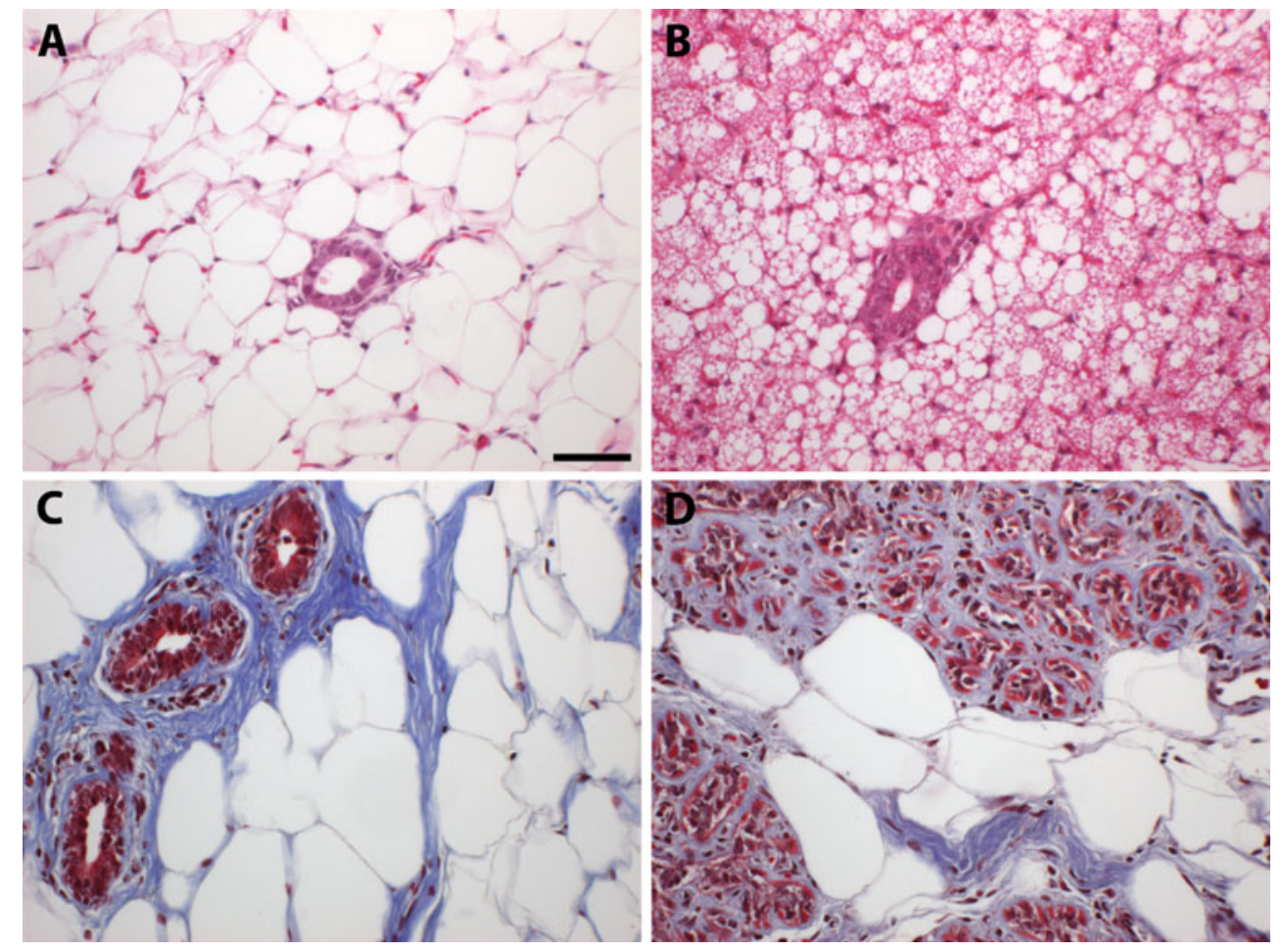
a continually-emerging theme concerning any role for the connective tissue stroma and its associated adipocytes within the mammary glands are the striking differences in this tissue compartment across species. This question ultimately raises important issues about whether the mammary fat pad in mice and the associated adipocytes fully recapitulate this environment in humans or economically-significant livestock species (Fig. 1).

Acknowledgments Lucila Aimo is supported by a DOD Postdoctoral fellowship W81XWH-09-1-0657.

Open Access This article is distributed under the terms of the Creative Commons Attribution Noncommercial License which permits any noncommercial use, distribution, and reproduction in any medium, provided the original author(s) and source are credited.

\section{References}

1. Hovey RC, Trott JF, Vonderhaar BK. Establishing a framework for the functional mammary gland: from endocrinology to morphology. J Mammary Gland Biol Neoplasia. 2002;7(1):17-38.

2. Watson CJ. Involution: apoptosis and tissue remodelling that convert the mammary gland from milk factory to a quiescent organ. Breast Cancer Res. 2006;8(2):203.

3. Brisken C, Rajaram RD. Alveolar and lactogenic differentiation. J Mammary Gland Biol Neoplasia. 2006;11(3-4):239-48.

4. Neville MC, Medina D, Monks J, Hovey RC. The mammary fat pad. J Mammary Gland Biol Neoplasia. 1998;3(2):109-16.

5. Hovey RC, McFadden TB, Akers RM. Regulation of mammary gland growth and morphogenesis by the mammary fat pad: a species comparison. J Mammary Gland Biol Neoplasia. 1999;4 (1):53-68.

6. Hoshino K. Mammary transplantation and its histogenesis in mice. In: Yokoyama A, Mizuno $H$, Nagasawa $H$, editors. Physiology of mammary glands. Tokyo: Japan Scientific Press; 1978. p. 163-228.

7. Tucker HA. Quantitative estimates of mammary growth during various physiological states: a review. J Dairy Sci. 1987;70 (9): 1958-66.

8. Cinti S. The adipose organ. Prostaglandins Leukot Essent Fatty Acids. 2005;73(1):9-15.

9. Hansen JB, Kristiansen K. Regulatory circuits controlling white versus brown adipocyte differentiation. Biochem J. 2006;398 (2):153-68.

10. Cinti S. Reversible physiological transdifferentiation in the adipose organ. Proc Nutr Soc. 2009;68(4):340-9.

11. Cousin B, Cinti S, Morroni M, Raimbault S, Ricquier D, Penicaud L, et al. Occurrence of brown adipocytes in rat white adipose tissue: molecular and morphological characterization. J Cell Sci. 1992;103(Pt 4):931-42.

12. Hens JR, Wysolmerski JJ. Key stages of mammary gland development: molecular mechanisms involved in the formation of the embryonic mammary gland. Breast Cancer Res. 2005;7 (5):220-4.

13. Sakakura T. Mammary embryogenesis. In: Neville MC, Daniel $\mathrm{CW}$, editors. The mammary gland: development, regulation, and function. New York: Plenum Press; 1987. p. 37-66.

14. Anbazhagan R, Bartek J, Monaghan P, Gusterson BA. Growth and development of the human infant breast. Am $\mathrm{J}$ Anat. 1991;192(4):407-17.
15. Anbazhagan R, Gusterson BA. Ultrastructure and immunohistochemistry of the embryonic type of fat identified in the human infant breast. Anat Rec. 1995;241(1):129-35.

16. Sheffield LG. Organization and growth of mammary epithelia in the mammary gland fat pad. J Dairy Sci. 1988;71(10):2855-74.

17. Mayer G, Klein M. HIstology and cytology of the mammary gland. In: Kon SK, Cowie AT, editors. Milk: the mammary gland and its secretion. New York: Academic; 1961. p. 47-116.

18. Hovey RC, Auldist DE, Mackenzie DD, McFadden TB. Preparation of an epithelium-free mammary fat pad and subsequent mammogenesis in ewes. J Anim Sci. 2000;78(8):2177-85.

19. Ellis S, McFadden TB, Akers RM. Prepuberal ovine mammary development is unaffected by ovariectomy. Domest Anim Endocrinol. 1998;15(4):217-25.

20. Nelson LW, Kelly WA. Changes in canine mammary gland histology during the estrous cycle. Toxicol Appl Pharmacol. 1974;27(1):113-22.

21. Schedin P, Hovey RC. Editorial: The mammary stroma in normal development and function. J. Mammary Gland Biol. Neoplasia. 2010.

22. Bani-Sacchi T, Bianchi S, Bani G, Bigazzi M. Ultrastructural studies on white adipocyte differentiation in the mouse mammary gland following estrogen and relaxin. Acta Anat (Basel). 1987;129(1):1-9.

23. Matsumoto M, Nishinakagawa H, Kurohmaru M, Hayashi Y. Effects of estrogen and progesterone on the parenchyma and blood vessels of the mammary gland in ovariectomized adult mice. J Vet Med Sci. 1995;57(1):39-44.

24. Matsumoto $M$, Nishinakagawa $H$, Kurohmaru M, Hayashi $Y$, Otsuka J. Effects of estrogen and progesterone on the development of the mammary gland and the associated blood vessels in ovariectomized mice. J Vet Med Sci. 1992;54(6):1117-24.

25. Matsumoto M, Nishinakagawa $H$, Kurohmaru M, Hayashi $Y$, Awal MA. Ultrastructural changes in fat cells and blood capillaries of the mammary gland in starved mice. J Vet Med Sci. 1995;57(4):733-6.

26. Gouon-Evans V, Pollard JW. Unexpected deposition of brown fat in mammary gland during postnatal development. Mol Endocrinol. 2002;16(11):2618-27.

27. Barbatelli G, Murano I, Madsen L, Hao Q, Jimenez M, Kristiansen K, et al. The emergence of cold-induced brown adipocytes in mouse white fat depots is determined predominantly by white to brown adipocyte transdifferentiation. Am J Physiol Endocrinol Metab. 298(6):E1244-253.

28. Master SR, Hartman JL, D'Cruz CM, Moody SE, Keiper EA, Ha SI, et al. Functional microarray analysis of mammary organogenesis reveals a developmental role in adaptive thermogenesis. Mol Endocrinol. 2002;16(6):1185-203.

29. Andres A-C, Djonov V. The mammary gland vasculature revisited. J. Mammary Gland Biol. Neoplasia 2010.

30. Soemarwoto IN, Bern HA. The effect of hormones on the vascular pattern of the mouse mammary gland. Am J Anat. 1958;103(3):403-35.

31. Hovey RC, Goldhar AS, Baffi J, Vonderhaar BK. Transcriptional regulation of vascular endothelial growth factor expression in epithelial and stromal cells during mouse mammary gland development. Mol Endocrinol. 2001;15(5):819-31.

32. Bianchi S, Bani G, Bigazzi M. Effects of relaxin on the mouse mammary gland. III. The fat pad. J Endocrinol Invest. 1986;9 (2): $153-60$

33. Tang W, Zeve D, Suh JM, Bosnakovski D, Kyba M, Hammer $\mathrm{RE}$, et al. White fat progenitor cells reside in the adipose vasculature. Science. 2008;322(5901):583-6.

34. Pujol E, Proenza AM, Roca P, Llado I. Changes in mammary fat pad composition and lipolytic capacity throughout pregnancy. Cell Tissue Res. 2006;323(3):505-11. 
35. Elias JJ, Pitelka DR, Armstrong RC. Changes in fat cell morphology during lactation in the mouse. Anat Rec. 1973;177 (4):533-47.

36. Bartley JC, Emerman JT, Bissell MJ. Metabolic cooperativity between epithelial cells and adipocytes of mice. Am J Physiol. 1981;241(5):C204-8.

37. Bandyopadhyay GK, Lee LY, Guzman RC, Nandi S. Effect of reproductive states on lipid mobilization and linoleic acid metabolism in mammary glands. Lipids. 1995;30(2):155-62.

38. Rebuffe-Scrive M, Eldh J, Hafstrom LO, Bjorntorp P. Metabolism of mammary, abdominal, and femoral adipocytes in women before and after menopause. Metabolism. 1986;35(9):792-7.

39. Rink JD, Simpson ER, Barnard JJ, Bulun SE. Cellular characterization of adipose tissue from various body sites of women. J Clin Endocrinol Metab. 1996;81(7):2443-7.

40. Anzai T, Muto K, Komine S. Changes in fat content and some characteristics of lipolytic activity during pregnancy and lactation in mouse mammary gland. Endocrinol Jpn. 1979;26(3):371-7.

41. Scow RO, Chernick SS, Fleck TR. Lipoprotein lipase and uptake of triacylglycerol, cholesterol and phosphatidylcholine from chylomicrons by mammary and adipose tissue of lactating rats in vivo. Biochim Biophys Acta. 1977;487(2):297-306.

42. Russell TD, Palmer CA, Orlicky DJ, Fischer A, Rudolph MC, Neville MC, et al. Cytoplasmic lipid droplet accumulation in developing mammary epithelial cells: roles of adipophilin and lipid metabolism. J Lipid Res. 2007;48(7):1463-75.

43. Lejour M. Evaluation of fat in breast tissue removed by vertical mammaplasty. Plast Reconstr Surg. 1997;99(2):386-93.

44. Ramsay DT, Kent JC, Hartmann RA, Hartmann PE. Anatomy of the lactating human breast redefined with ultrasound imaging. $\mathrm{J}$ Anat. 2005;206(6):525-34.

45. Vandeweyer E, Hertens D. Quantification of glands and fat in breast tissue: an experimental determination. Ann Anat. 2002;184(2):181-4.

46. Anastassiades OT, Spiliades C, Tsakraklides E, Gogas J. Amount and distribution of solid and fatty tissues in the female breast and their relationship to carcinoma. Pathol Res Pract. 1983;176(24):200-15.

47. Lilla JN, Joshi RV, Craik CS, Werb Z. Active plasma kallikrein localizes to mast cells and regulates epithelial cell apoptosis, adipocyte differentiation, and stromal remodeling during mammary gland involution. J Biol Chem. 2009;284(20):13792-803.

48. Alexander CM, Selvarajan S, Mudgett J, Werb Z. Stromelysin-1 regulates adipogenesis during mammary gland involution. J Cell Biol. 2001;152(4):693-703.

49. Howard BA, Gusterson BA. Human breast development. J Mammary Gland Biol Neoplasia. 2000;5(2):119-37.

50. Oliver SP, Sordillo LM. Udder health in the periparturient period. J Dairy Sci. 1988;71(9):2584-606.

51. Capuco AV, Akers RM, Smith JJ. Mammary growth in Holstein cows during the dry period: quantification of nucleic acids and histology. J Dairy Sci. 1997;80(3):477-87.

52. De Vries LD, Dover H, Casey T, VandeHaar MJ, Plaut K. Characterization of mammary stromal remodeling during the dry period. J Dairy Sci. 93(6):2433-43.

53. Wang P, Mariman E, Renes J, Keijer J. The secretory function of adipocytes in the physiology of white adipose tissue. J Cell Physiol. 2008;216(1):3-13.

54. Celis JE, Moreira JM, Cabezon T, Gromov P, Friis E, Rank F, et al. Identification of extracellular and intracellular signaling components of the mammary adipose tissue and its interstitial fluid in high risk breast cancer patients: toward dissecting the molecular circuitry of epithelial-adipocyte stromal cell interactions. Mol Cell Proteomics. 2005;4(4):492-522.

55. Trott JF, Vonderhaar BK, Hovey RC. Historical perspectives of prolactin and growth hormone as mammogens, lactogens and galactagogues - agog for the future! J Mammary Gland Biol Neoplasia. 2008;13(1):3-11.

56. Zinger M, McFarland M, Ben-Jonathan N. Prolactin expression and secretion by human breast glandular and adipose tissue explants. J Clin Endocrinol Metab. 2003;88(2):689-96.

57. Hugo ER, Borcherding DC, Gersin KS, Loftus J, Ben-Jonathan N. Prolactin release by adipose explants, primary adipocytes, and LS14 adipocytes. J Clin Endocrinol Metab. 2008;93(10):400612 .

58. Hovey RC, Trott JF, Ginsburg E, Goldhar A, Sasaki MM, Fountain SJ, et al. Transcriptional and spatiotemporal regulation of prolactin receptor mRNA and cooperativity with progesterone receptor function during ductal branch growth in the mammary gland. Dev Dyn. 2001;222(2):192-205.

59. Nakatani H, Aoki N, Okajima T, Nadano D, Flint D, Matsuda T. Establishment of a mammary stromal fibroblastic cell line for in vitro studies in mice of mammary adipocyte differentiation. Biol Reprod. 82(1):44-53.

60. Viengchareun S, Servel N, Feve B, Freemark M, Lombes M, Binart N. Prolactin receptor signaling is essential for perinatal brown adipocyte function: a role for insulin-like growth factor-2. PLoS ONE. 2008;3(2):e1535.

61. Freemark M, Fleenor D, Driscoll P, Binart N, Kelly P. Body weight and fat deposition in prolactin receptor-deficient mice. Endocrinology. 2001;142(2):532-7.

62. Ling C, Svensson L, Oden B, Weijdegard B, Eden B, Eden S, et al. Identification of functional prolactin (PRL) receptor gene expression: PRL inhibits lipoprotein lipase activity in human white adipose tissue. J Clin Endocrinol Metab. 2003;88(4):1804 8.

63. Santen RJ, Brodie H, Simpson ER, Siiteri PK, Brodie A. History of aromatase: saga of an important biological mediator and therapeutic target. Endocr Rev. 2009;30(4):343-75.

64. Chow JD, Simpson ER, Boon WC. Alternative 5'-untranslated first exons of the mouse Cyp19A1 (aromatase) gene. J Steroid Biochem Mol Biol. 2009;115(3-5):115-25.

65. Feuermann Y, Mabjeesh SJ, Shamay A. Mammary fat can adjust prolactin effect on mammary epithelial cells via leptin and estrogen. Int J Endocrinol. 2009;2009:427260.

66. Peaker M, Taylor E. Oestrogen production by the goat mammary gland: transient aromatase activity during late pregnancy. J Endocrinol. 1990;125(1):R1-3.

67. Mueller SO, Clark JA, Myers PH, Korach KS. Mammary gland development in adult mice requires epithelial and stromal estrogen receptor alpha. Endocrinology. 2002;143(6):2357-65.

68. Meyer MJ, Capuco AV, Boisclair YR, Van Amburgh ME. Estrogen-dependent responses of the mammary fat pad in prepubertal dairy heifers. J Endocrinol. 2006;190(3):819-27.

69. Dieudonne MN, Leneveu MC, Giudicelli Y, Pecquery R. Evidence for functional estrogen receptors alpha and beta in human adipose cells: regional specificities and regulation by estrogens. Am J Physiol Cell Physiol. 2004;286(3):C655-61.

70. Cunha GR, Young P, Hom YK, Cooke PS, Taylor JA, Lubahn DB. Elucidation of a role for stromal steroid hormone receptors in mammary gland growth and development using tissue recombinants. J Mammary Gland Biol Neoplasia. 1997;2 (4):393-402.

71. Cheng G, Weihua Z, Warner M, Gustafsson JA. Estrogen receptors ER alpha and ER beta in proliferation in the rodent mammary gland. Proc Natl Acad Sci USA. 2004;101(11):3739-46.

72. Li S, Han B, Liu G, Ouellet J, Labrie F, Pelletier G. Immunocytochemical localization of sex steroid hormone receptors in normal human mammary gland. J Histochem Cytochem. 58(6):509-15.

73. Meyer MJ, Rhoads RP, Capuco AV, Connor EE, Hummel A, Boisclair YR, et al. Ontogenic and nutritional regulation of 
steroid receptor and IGF-I transcript abundance in the prepubertal heifer mammary gland. J Endocrinol. 2007;195(1):59-66.

74. Rowzee AM, Lazzarino DA, Rota L, Sun Z, Wood TL. IGF ligand and receptor regulation of mammary development. J Mammary Gland Biol Neoplasia. 2008;13(4):361-70.

75. Kleinberg DL, Ruan W. IGF-I, GH, and sex steroid effects in normal mammary gland development. J Mammary Gland Biol Neoplasia. 2008;13(4):353-60.

76. Richert MM, Wood TL. The insulin-like growth factors (IGF) and IGF type I receptor during postnatal growth of the murine mammary gland: sites of messenger ribonucleic acid expression and potential functions. Endocrinology. 1999;140 (1):454-61.

77. Walden PD, Ruan W, Feldman M, Kleinberg DL. Evidence that the mammary fat pad mediates the action of growth hormone in mammary gland development. Endocrinology. 1998;139(2):65962.

78. Hovey RC, Davey HW, Mackenzie DD, McFadden TB. Ontogeny and epithelial-stromal interactions regulate IGF expression in the ovine mammary gland. Mol Cell Endocrinol. 1998;136(2):139-44.

79. Rahimi N, Saulnier R, Nakamura T, Park M, Elliott B. Role of hepatocyte growth factor in breast cancer: a novel mitogenic factor secreted by adipocytes. DNA Cell Biol. 1994;13 (12):1189-97.

80. Kilroy GE, Foster SJ, Wu X, Ruiz J, Sherwood S, Heifetz A, et al. Cytokine profile of human adipose-derived stem cells: expression of angiogenic, hematopoietic, and pro-inflammatory factors. J Cell Physiol. 2007;212(3):702-9.

81. Zhang HZ, Bennett JM, Smith KT, Sunil N, Haslam SZ. Estrogen mediates mammary epithelial cell proliferation in serum-free culture indirectly via mammary stroma-derived hepatocyte growth factor. Endocrinology. 2002;143(9):3427-34.

82. Ehrhart EJ, Segarini P, Tsang ML, Carroll AG, Barcellos-Hoff MH. Latent transforming growth factor betal activation in situ: quantitative and functional evidence after low-dose gammairradiation. FASEB J. 1997;11(12):991-1002.

83. Soriano JV, Pepper MS, Orci L, Montesano R. Roles of hepatocyte growth factor/scatter factor and transforming growth factor-beta1 in mammary gland ductal morphogenesis. J Mammary Gland Biol Neoplasia. 1998;3(2):133-50.

84. Maccio A, Madeddu C, Mantovani G. Adipose tissue as target organ in the treatment of hormone-dependent breast cancer: new therapeutic perspectives. Obes Rev. 2009;10(6):660-70.

85. Lin Y, Li Q. Expression and function of leptin and its receptor in mouse mammary gland. Sci China C Life Sci. 2007;50(5):66975.

86. Kamikawa A, Ichii O, Yamaji D, Imao T, Suzuki C, OkamatsuOgura Y, et al. Diet-induced obesity disrupts ductal development in the mammary glands of nonpregnant mice. Dev Dyn. 2009;238(5):1092-9.

87. Thorn SR, Giesy SL, Myers MG, Jr., Boisclair YR. Mammary ductal growth is impaired in mice lacking leptin-dependent signal transducer and activator of Transcription 3 signaling. Endocrinology.

88. Thorn SR, Meyer MJ, Van Amburgh ME, Boisclair YR. Effect of estrogen on leptin and expression of leptin receptor transcripts in prepubertal dairy heifers. J Dairy Sci. 2007;90 (8):3742-50.

89. Landskroner-Eiger S, Qian B, Muise ES, Nawrocki AR, Berger JP, Fine EJ, et al. Proangiogenic contribution of adiponectin toward mammary tumor growth in vivo. Clin Cancer Res. 2009;15(10):3265-76.

90. Perrier S, Caldefie-Chezet F, Vasson MP. IL-1 family in breast cancer: potential interplay with leptin and other adipocytokines. FEBS Lett. 2009;583(2):259-65.
91. Russell JS, McGee SO, Ip MM, Kuhlmann D, Masso-Welch PA. Conjugated linoleic acid induces mast cell recruitment during mouse mammary gland stromal remodeling. J Nutr. 2007;137 (5):1200-7.

92. Bell LN, Cai L, Johnstone BH, Traktuev DO, March KL, Considine RV. A central role for hepatocyte growth factor in adipose tissue angiogenesis. Am J Physiol Endocrinol Metab. 2008;294(2):E336-44.

93. Knazek RA, Liu SC, Bodwin JS, Vonderhaar BK. Requirement of essential fatty acids in the diet for development of the mouse mammary gland. J Natl Cancer Inst. 1980;64(2):37782.

94. Miyamoto-Tiaven MJ, Hillyard LA, Abraham S. Influence of dietary fat on the growth of mammary ducts in BALB/c mice. $J$ Natl Cancer Inst. 1981;67(1):179-88.

95. Welsch CW, DeHoog JV, O’Connor DH, Sheffield LG. Influence of dietary fat levels on development and hormone responsiveness of the mouse mammary gland. Cancer Res. 1985;45(12 Pt 1):614754

96. Sejrsen K, Purup S, Vestergaard M, Foldager J. High body weight gain and reduced bovine mammary growth: physiological basis and implications for milk yield potential. Domest Anim Endocrinol. 2000;19(2):93-104.

97. Meyer MJ, Capuco AV, Ross DA, Lintault LM, Van Amburgh ME. Developmental and nutritional regulation of the prepubertal bovine mammary gland: II. Epithelial cell proliferation, parenchymal accretion rate, and allometric growth. J Dairy Sci. 2006;89(11):4298-304.

98. Beck JC, Hosick HL. Growth of mouse mammary epithelium in response to serum-free media conditioned by mammary adipose tissue. Cell Biol Int Rep. 1988;12(2):85-97.

99. Bandyopadhyay GK, Hwang S, Imagawa W, Nandi S. Role of polyunsaturated fatty acids as signal transducers: amplification of signals from growth factor receptors by fatty acids in mammary epithelial cells. Prostaglandins Leukot Essent Fatty Acids. 1993;48(1):71-8.

100. Pohlmeier WE, Hovey RC, Van Eenennaam AL. Reproductive abnormalities in mice expressing omega-3 fatty acid desaturase in their mammary glands. Transgenic Res.

101. Peaker M. Endocrine signals from the mammary gland. J Endocrinol. 1995;147(2):189-93.

102. Clegg RA. Lipoprotein lipase. Localization on plasma membrane fragments from lactating rat mammary tissue. Biochim Biophys Acta. 1981;664(2):397-408.

103. Levay-Young BK, Bandyopadhyay GK, Nandi S. Linoleic acid, but not cortisol, stimulates accumulation of casein by mouse mammary epithelial cells in serum-free collagen gel culture. Proc Natl Acad Sci USA. 1987;84(23):8448-52.

104. Pauloin A, Chat S, Pechoux C, Hue-Beauvais C, Droineau S, Galio L, et al. Oleate and linoleate stimulate degradation of betacasein in prolactin-treated $\mathrm{HC11}$ mouse mammary epithelial cells. Cell Tissue Res. 340(1):91-102.

105. Sigurdson SL, Ip MM. Casein accumulation by rat mammary epithelial cells grown within a reconstituted basement membrane is modulated by fatty acids in a hormone- and time-dependent manner. Exp Cell Res. 1993;208(2):333-43.

106. Levine JF, Stockdale FE. 3T3-L1 adipocytes promote the growth of mammary epithelium. Exp Cell Res. 1984;151 (1):112-22.

107. Hovey RC, MacKenzie DD, McFadden TB. The proliferation of mouse mammary epithelial cells in response to specific mitogens is modulated by the mammary fat pad in vitro. In Vitro Cell Dev Biol Anim. 1998;34(5):385-92.

108. Carrington CA, Hosick HL. Effects of dietary fat on the growth of normal, preneoplastic and neoplastic mammary epithelial cells in vivo and in vitro. J Cell Sci. 1985;75:269-78. 
109. Davidenko N, Campbell JJ, Thian ES, Watson CJ, Cameron RE. Collagen-hyaluronic acid scaffolds for adipose tissue engineering. Acta Biomater.

110. Faulkin Jr LJ, Deome KB. Regulation of growth and spacing of gland elements in the mammary fat pad of the $\mathrm{C} 3 \mathrm{H}$ mouse. $\mathrm{J}$ Natl Cancer Inst. 1960;24:953-69.

111. Berry SD, Howard RD, Jobst PM, Jiang H, Akers RM. Interactions between the ovary and the local IGF-I axis modulate mammary development in prepubertal heifers. J Endocrinol. 2003;177(2):295-304.

112. Hoshino K. Transplantability of mammary gland in brown fat pads of mice. Nature. 1967;213(5072):194-5.

113. Blair PB, Moretti RL. The mammary fat pad as a privileged transplantation site. Transplantation. 1967;5(3):542-4.

114. Miller FR, Medina D, Heppner GH. Preferential growth of mammary tumors in intact mammary fatpads. Cancer Res. 1981;41(10):3863-7.

115. Elliott BE, Tam SP, Dexter D, Chen ZQ. Capacity of adipose tissue to promote growth and metastasis of a murine mammary carcinoma: effect of estrogen and progesterone. Int $\mathrm{J}$ Cancer. 1992;51(3):416-24.
116. Welsch CW, O'Connor DH, Aylsworth CF, Sheffield LG. Normal but not carcinomatous primary rat mammary epithelium: readily transplanted to and maintained in the athymic nude mouse. J Natl Cancer Inst. 1987;78(3):557-65.

117. Proia DA, Kuperwasser C. Reconstruction of human mammary tissues in a mouse model. Nat Protoc. 2006;1(1):206-14.

118. Couldrey C, Moitra J, Vinson C, Anver M, Nagashima K, Green J. Adipose tissue: a vital in vivo role in mammary gland development but not differentiation. Dev Dyn. 2002;223(4):45968.

119. Landskroner-Eiger S, Park J, Israel D, Pollard JW, Scherer PE. Morphogenesis of the developing mammary gland: Stagedependent impact of adipocytes. Dev Biol.

120. Booth BW, Boulanger CA, Smith GH. Stem cells and the mammary microenvironment. Breast Dis. 2008;29:57-67.

121. Illouz YG, Sterodimas A. Autologous fat transplantation to the breast: a personal technique with 25 years of experience. Aesthet Plast Surg. 2009;33(5):706-15.

122. Mizuno H, Hyakusoku H. Fat grafting to the breast and adiposederived stem cells: recent scientific consensus and controversy. Aesthet Surg J. 30(3):381-7. 